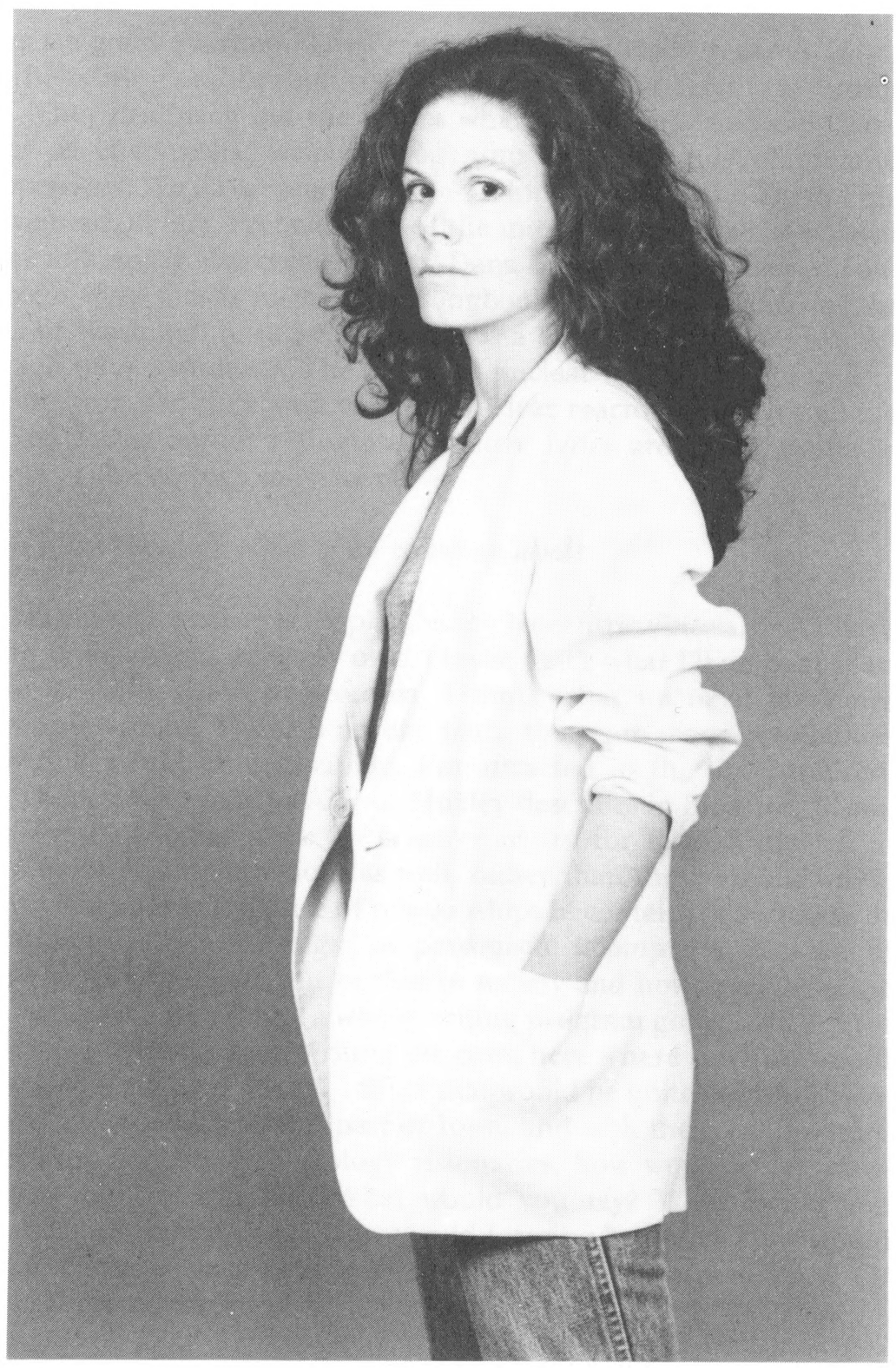




\section{INTERVIEW WITH ELIZABETH TALLENT}

Karen Adelman

ELIZABETH TALLENT IS the author of two short story collections, In Constant Flight and Time With Children; a novel, Musuem Pieces; and a book of criticism, Married Men and Magic Tricks: John Updike's Erotic Heroes. Her fiction has appeared in The New Yorker, Grand Street, Paris Review, Harper's, and Esquire; has won an O. Henry Award and a Pushcart Prize, and twice been in Best American Short Stories. Her work has been anthologized in Sudden Fiction, The Editor's Choice, and The Esquire Fiction Reader. The following interview was conducted in April 1989, after her first of two semesters teaching at the Iowa Writers' Workshop.

The permutations of marriage, love, infidelity, and the children springing from them have been your subjects. You've said that you see these in terms of a larger theme, that of "belonging," as one person might belong to another. Can you expand on that?

I think that I was interested in what you get when you love someone, how much you get, how reliable it is, and how you redefine it-how you redefine it and how the two people redefine it together. Can they redefine it out of existence, or does some core of affection assert itself? Those seem like variations of a kind of story to me, which is: How you live. How you live with someone, or not. If you can't live with them, how do you decide to leave. I think those are, to me, the most fascinating stories of all.

Do you have any sense of the roots of that fascination?

Hmm. An abiding, ah, existential, sort of insecurity? [Laughs] A massive hatred of loss of all kinds, of erosion of trust. Those are my emotional instincts. Whatever gets to you at the deepest place. I 
certainly have the strongest responses to those things in my life and to what I'm writing about.

I was writing about what happens to children for a long time before we decided to have a child. People were always surprised. They would come up after a reading and they wouldn't even ask me if I had children, they would just say, "How old are your children?" I would have to say, "I don't have any." Finally, finally it happened that someone came up and said, "How old are your children?" I just looked at her and I said, "Well, I'm pregnant. [Laughs] Finally pregnant."

I was curious as to how actually having a child had changed your fiction-if at all.

It changes your emotional life so radically; you feel that your sense of values has gone through a real turnover. You can't imagine that it's not affecting your work, but I don't see it yet. It might be that, like a lot of significant emotional stuff, there's this delay before it really hits the work. The stories I'm writing now don't seem to me far away from the stories in Time With Children. They may be more obsessive than ever, actually more focused about children, even than before, and I was already pretty focused.

So the actual experience of having a child was one of realizing that you had already understood it, but that it was even more so?

You hate to claim that, because you don't want to claim prescience, because you know how often you're really wrong about interpreting emotions.

Frank [Conroy] was talking about writing something that then happens to you, and the eeriness of that. I find it a lot. I find it really true. It just happened yesterday: In the thing that I was writing, the narrator was a poet. She said, "in workshop I just had a poem that was written about this." Her feeling was: It doesn't help that your experiences are common experience. There's nothing in that that can allay your sorrow, if it's something terrible. Then yesterday I read a piece of student work that was exactly about something that just happened to me. Anyway, I was perfectly right. [Laughs] Did that make any sense at all? I'd just written about this poet who was doing something that had just happened to her. Well $I$ just read a piece of student work in my real life-it's sort of unnerving-it's just exactly what I'd just gone through. You chew your fingernails, you just don't know what to make of it. You finally get forced to regard it as a mysterious process, even if you're very given to materialistic thinking, 
like I am. It gets forced on you. There's something mysterious about writing.

In addition to your fiction you've written reviews and articles for Architectural Digest and a book about John Updike's work. I think it was Updike who said that a writer should be able to write essays, criticism, fiction, everything. How do those kinds of writing interact in your life?

In a really good way for me. Because there's a kind of relief in not making things up but going and talking to people and finding out as much as you can about the way they think about things. You feel you have this fairly intimate access all of a sudden, to a totally other point of view about the world, and you can always use that if you're a fiction writer. To get to go into people's houses-rich people's houses-and look at all their things, and have them talk about the paintings on the walls and they got the ceiling beams from some sixteenth-century Spanish Church, and their ex-husband put this hammer dent in the wall. You're just hearing all these stories. You get invited in. Writers need a lot of being invited in. I think it balances us when we want to invent to have had a fair amount of exposure to other people's thinking.

So you're able both to find that mystery you were talking about before in non-fictonal circumstances and to take non-fictional circumstances and turn them into the mystery for other fictional purposes.

There's a kind of thing you're interested in, so anything that falls within this range of things that are attractive to you, interesting to you-I'm always interested in people's houses, and people's love lives. You want to know as much as you can about them, but if you're not one of those writers who's really, really outgoing and assertive, it helps to have a job to do it. Actually you have to go and talk to these people, have to get out of the house and away from the typewriter for a while.

How do you compare the experience of writing related stories with the experience of writing a novel?

My sense of form in stories is a little more sure-footed. In the novel I felt I kept having to make these jumps, and I could never understand how much of a jump I'd have to make. Or whether I'd made the right jump once I'd tried it. It's much more a fitful, quizzical process for me. Very often with linked stories there's some point in the first story that I know could generate a second story, or I have a feeling there's 
something unfinished that's kind of floating. Sometimes I don't get it again-it's just an aspect of the story to have that unfinished edge to it. I like that as well. Existence itself does not occur to us as perfectly finished segments. A story that has a certain fuzziness is often reflecting some kind of experience more accurately than one that makes a perfect transition from unawareness to epiphany and to the end of the story.

Is there less room for those fuzzy edges in the novel, then?

I'm thinking about a second novel that would have a blurred outer boundary. People would get into it and they would not be there again. When I started thinking about this novel that way, where people would just disappear from it and you wouldn't pick up those threads again, I got more interested in doing another novel. My sense of the novel form is that it's so much more demanding than stories because you have so much more to keep track of. You can't understand at all when you begin it how those elements will affect the course of the story. It's really much more of a sense of wait and see for me with a novel.

So you're getting away from the feeling that you have to structure the novel a certain way.

Yes. It came from reading Portrait of the Artist for my seminar. [Richard] Ellmann talks about Joyce's tactic of the blurred margin where you really don't have a finishedness to the story at all. I could have gotten that myself from reading Joyce; it somehow was this critical interpretation of it. It's recent. It's just really started to appeal to me. And since I'm committed to writing another novel ...

Oh, you are?

I sold two books and one of them's a novel. [Laughs] So it has this enlivening ... reality of actually being bought. [Laughs]

About the structure of your short stories. Reviewers wrote of the stories in In Constant Flight as composed of a "sequence of images," of "accretions of small discoveries moving toward a conclusion rather than a climax" (Erdrich), and therefore as being "on the border of poetry" (Sumnor). It's interesting that you're talking about these structural fuzzy edges in the novel, because it seemed 
that you were evolving away from that kind of fuzzy edge in your short stories. Is that true?

I guess I see it as like a segue. Several of those stories acutely turned on a particular incident, and things were finished after that; there was this click of closure that was - I think you're right to see that it was new for me. After that book, though, the next story that I wrote got turned down by The New Yorker because there wasn't any sort of classical . . . nothing got wrapped up. I thought about it really hard, and what I liked was its generous way of just having things happen. And then it didn't resolve things either in terms of an epiphany or imagistically. In fact, it ends before this woman goes into labor. So it ends right on the brink of this bigger biological and emotional event, which would be much more the terrain of a traditional story. It ends right, bam, before that.

But Time With Children had more stories structured in a more traditional way than In Constant Flight.

Yes. Some of them. In In Constant Flight I was determined not to do that. I really wanted to play with a diffuse quality, an open-endedness. And that was as conscious as I can be about my own work. I knew that that was what I wanted to do. In the next book there was a reaction against that, a willingness to say: This can be accomplished in terms of recognition as well. And then they also got more plotted. There are a lot of writers who start diffuse, and then they gradually acquire plot. It's more unusual for it to come in the other way around: you find someone who's not interested in the pyrotechnics of language but can write good plots. That person isn't as likely to turn out to be a writer, I think, because you have to start from some kind of bottom infatuation with language. Nadine Gordimer talks about that. She says that often it's women writers who'll be given to lyricism in their early work, and then slowly they acquire plot. I think her thesis is plot doesn't come easily to women, who tend to think in non-linear ways - she's almost making a cultural appraisal of it. But I did get so that plot was no longer intolerable to me.

And is the fuzzy-edged novel a reaction to that?

It could be. Just like finally you write a novel out of reaction to having written a certain number of stories. You just feel this yen to do something that's un-storylike, that's longer. Meanwhile, to get away from stories maybe you're doing that Updikean thing of trying 
reviews and writing non-fiction, so you have a relief from working in stories all the time.

In In Constant Flight the first person present tense was really predominant, whereas in Time With Children third person past was most common. I'm interested in what theories you might have about the present tense in general thematic implications for stories that use it.

I don't think I'm going to be terribly original on that subject. There's [Charles] Baxter's comment on the ahistorical quality of present tense. You see, it's really unlikely I think about that. I often hear a first line, and whatever tense it's in seems to be unchangeable to me. If I try and cast it in another tense I blow the whole story. If I try and change the first sentence at all I lose the story. Even where I sort of think, "Here are four stories in a row that are present tense, it's time to work on a different palette, you know, have some different verbs here," I can't. I'm more or less committed to it from the first sentence on. A lot of times there will be some sentence, even if it isn't the first sentence, there'll be some sentence that I'm hearing that is so crucial to the story that that change couldn't be made, I couldn't change the tense.

The Hart and Caro stories are in present, whereas the Sam and Jenny stories are in past tense. So it was just a matter of what you heard when you started to write it?

When I got to the last line of the first Sam and Jenny story, there was the phrase "to warm them or be warmed, she couldn't have said." I knew it couldn't end except with "said." There was no way it was going to be "she couldn't say." It just doesn't have the same. . . . So at some point you look at it and you think-it's not that you could change it-but you think, "Oh, yeah, that was right, and that was why it was in that tense." And they always seem to stay, whatever tense the lead stories were in, they seem to stay. So Hart and Caro seemed present tense all the way through.

So you didn't have to make a conscious decision to keep the linked stories?

You wouldn't have to, because they don't come to you that way. Even if you were thinking, "Well, I'd really like to write another story about that couple," you might not be able to do it. I'd like to write a story about Hart and Caro where they have the baby, where they're in the hospital. But I don't know if I get to or not. I have to wait on it. See in a novel, if you knew you needed that scene, you could start, you 
could just start trying to rough it in, or you could tackle it, [if] you knew that scene was necessary for a novel, [if] you knew it. That's why it feels more homeworky to me, novels do.

Why do you think?

Because you need certain things. You can't just abandon people right before they're going into labor in a novel. [Laughs] It would be really cheating, because the reader would have this expectation that they're going to be close to these lives throughout the whole length of the novel. I'm traditional enough to think that's an entirely legitimate experience, and an emotional need. That if you're going to be closely involved with these characters for the length of a novel, you do want in. You want to be close. You don't want to be arbitrarily cut off or have your interests slighted.

So you just can't let go in the middle of a shape, but at the end of a shape you can.

Yes.

Here's another contrast. In In Constant Flight, the characters-white and educated-live in almost uncanny isolation from other classes and races. In Museum Pieces, however, a more complex social context begins to emerge. And with Time With Children almost every story concerns mixing, or interaction amongst different cultures. Can you talk about that progression?

I would see it as going all the way through all three books. But the contacts were much more slight in the first book, and then they got deeper. But I would see it as continuing all the way through. It would be a question of, I hope, getting more mature in my art, that the deeper work comes from the deeper conflict. For that, people have to be sparking contact with each other, and staying there, committed to staying where they are. So Time With Children is much more about having a home, and the commitment that if something goes wrong, you're there, and you're bound to try and work it out.

You've spoken of the landscape of the Southwest as one you find visually and morally attractive, and most of your stories are set in that area.

Yes.

It's interesting that it's an adopted region. You grew up in D.C., and you're 
moving to California in the autumn. How do you feel about leaving a region that's been such a big part of your work?

I think you only get one home, and that's home. We're going to be away from it for three-quarters of the year and summer there, keep a house there. That house will be the emotional crux of it. We have this house that ... we did everything, and most of it by hand, and most of it by a lot of scraping. I don't think you can really abandon a house like that without costing yourself a great deal. But it's also now true that I felt I had gotten enough of New Mexico that I could stay away for awhile. When I first got there I was like somebody starved for it. I had to know everything I could about it. I didn't want to leave, and now it's OK. It feels more like I'm carrying some of it with me. Whenever we'd leave New Mexico, I had a Perrier bottle and I'd fill it with Rio Grande river water, and just keep it. And the next time we went back I would empty it back into the Rio Grande. I didn't do that this time. I think I need to go home, and I need to get something to carry with me. I sort of thought I'd outgrown that, but maybe it's a good idea. I always kept that by my typewriter.

So you feel that your spiritual center, if you will, will remain there?

It feels immutable. It's a very serious bond to me, and I adore New Mexico. I miss it visually. I'm conscious of when I look at the horizon here of trying to make it more interesting to myself by putting some mesas in it, and cutting down those deciduous trees. [Laughs]

You're moving to Callfornia to teach. How does it feel to teach and juggle writing? Is that a problem, or do you like it?

I think it's a problem for everybody, except people who are utterly self-disciplined. But I'm not. You do this juggling act and sometimes you're happier with it than other times. But Erik Erokson talks about the Generative Stage in psychology, where finally you want to teach, or you want to be committed to people who are interested in the same thing you've always been doing, and you finally feel you have something to give them. In a crude way I think that's where I am. I think you reach a point in your life where without that you feel you're not giving anything back. And you want to. Maybe it's profoundly human, maybe it's natural. You get a wish to give back to people. 
How do you feel about the whole workshop phenomenon-as a writer who didn't go through it?

Ambivalent, interested, ambivalent. I'm really pleased when I see it work, because I feel it's confirming the promise of the thing. I have seen things happen that were good, and relationships, not necessarily between me and a certain student but even amongst students, that seemed really beneficial. But I'm also skeptical. Especially if people don't seem to be bringing a lot of life experience to the workshop. I think, "Ah, here's another two years in school." There's only so much that you can write about unless you've been out in the world. If I could do an ideal program, it would require three year's field work or travel abroad: Go to another culture and live there. Or go to the Southwest and teach English on a reservation. Some experience that was a departure from what you grew up with.

I guess the only thing that's left to ask you is whether you have a sense of where fiction is going or where you want it to go.

I have certain writers that I read everything they write. I think so much in terms of individual writers, and so little of fiction as a glacier. It really doesn't seem that way to me at all. Charles Baxter, he's a really interesting writer right now. Amy Hempel, though I haven't seen anything for awhile. I'm more interested now in young British writers, and what they can come up with. Not all English British. They have such a huge influx of different cultures there that you're getting some really interesting writing-people who are pitted against this sort of European culture, and come from totally, radically different places. But no, I don't have some sense of fiction as having a set of goals.

Well, do you have any messages for the world? [Laughs] Posterity?

[Laughs] No.

\section{WORKS CITED}

Erdrich, Louise. "Life in Shards and Fragments." Rev. of Museum Pieces, by Elizabeth Tallent. New York Times Book Review 7 April 1985:10.

Sumnor, Clare. "After Her Fashion." Rev. of In Constant Flight, by Elizabeth Tallent. Times Literary Supplement 16 Sept. 1983:1002. 